\title{
VALORIZATION OF SUGARCANE AND ORANGE BAGASSES IN THE BIOSORPTION PROCESS FOR REMOVAL OF DYE FROM THE SYNTHETIC AQUEOUS SOLUTION
}

\author{
Vitória Brocardo de Leon ${ }^{1}$, Claiton Zanini Brusamarello², Sheila Regina Oro ${ }^{1}$ and \\ Fernanda Batista de Souza ${ }^{1 *}$ \\ ${ }^{1}$ Universidade Tecnológica Federal do Paraná (UTFPR), Câmpus Francisco Beltrão, Programa \\ de Pós-graduação em Engenharia Ambiental: Análise e Tecnologia Ambienta (PPGEA), Linha Santa Bárbara s/n, \\ Francisco Beltrão, 85601-970, PR, Brazil \\ 2 Universidade Tecnológica Federal do Paraná (UTFPR), Câmpus Francisco Beltrão, Departamento Acadêmico de \\ Engenharias (DAENG), Linha Santa Bárbara s/n, Francisco Beltrão, CEP 85601-970, PR, Brazil
}

Received 16 April 2020; received in revised form 15 April 2021; accepted 10 October 2021

\begin{abstract}
Effluents from textile industries contain high dye concentrations, which, when inappropriately used, may interference with the process of light absorption by plants, impairing the photosynthesis process. Based on such assertions, this study aimed to analyze the biosorption process with sugarcane bagasse (SB) and orange bagasse (OB) for removal of the dye Neolan Black WA. For evaluating the influence of the $\mathrm{pH}$ of the dye solution, of the chemical treatment of the biosorbent and of the type of biosorbent on the adsorption process, a factorial design $2^{3}$ was elaborated. Then, the data from the experiments were statistically analyzed by analysis of variance (ANOVA) and Tukey test. In the Tukey test, the averages for dye removal were higher for SB than for OB, with removals of $100 \%$ and $65 \%$, respectively, and the best conditions obtained for SB were $\mathrm{pH} 2$ solution and chemically treated material. The results for $\mathrm{OB}$ were $\mathrm{pH} 2$ and material without chemical treatment. The SB and the $\mathrm{OB}$, before and after the treatment with sulfuric acid, were characterized using scanning electron microscopy (SEM) and adsorption and desorption isotherms of $\mathrm{N}_{2}(\mathrm{BET} / \mathrm{BJH})$, in which it was possible to observe structural changes in both materials due to the acid action.
\end{abstract}

Keywords: Adsorption; Sugarcane bagasse; Biosorption; Statistical design of the experiments.

(C) 2021 Journal of Urban and Environmental Engineering (JUEE). All rights reserved.

\footnotetext{
* Correspondence to: Fernanda B. Souza, Tel.: +55 463520 2671; Fax: +55 4635202600.

E-mail: fernandasouza@utfpr.edu.br
} 


\section{INTRODUCTION}

Throughout the industrial production process, different types of waste are produced, which can be liquid, solid or gaseous. When incorrectly disposed, such wastes may cause problems to the environment and the public health (Vijayaraghavan et al. 2013).

The liquid wastes from this activity are called industrial effluents, containing different physical, chemical and biological characteristics, which vary depending on the industrial sector, the raw material and the products used in the production process (Palma 2016).

In this context, the textile effluents are a major concern due to the presence of high levels of organic matter and minerals combined with an intense color, resulting from the contamination of the water used in the production process with synthetic dyes and chemical products (Brasil 1981, Leme 2014, Agarwal et al. 2019).

According to Guaratini and Zanoni (2005), the disposal of this type of effluent into water sources without adequate color removal treatment may interfere with the light absorption by plants and animals, which impairs the photosynthesis process.

Seeking alternatives to reduce or eliminate environmental impacts caused by the presence of dyes in textile effluents, the use of methods and technologies such as agro-industrial waste biosorption is proposed. Biosorption is defined as a process in which materials of vegetable or animal origin are used as adsorbents in the removal of particles and organic and inorganic molecules present in a solution (Iap 2009, Brasil 2011).

In this study, the removal potential of the textile dye Neolan Black WA from an aqueous solution by biosorption method, using orange and sugarcane bagasses, with and without chemical treatment as biosorbents was assessed. The effect of the chemical treatment of the materials, of the solution $\mathrm{pH}$ and of the type of biosorbent on the biosorption process was studied by using a factorial design $2^{3}$ and evaluated

\section{MATERIAL AND METHODS}

\section{Production of biosorbents}

The orange bagasse $(\mathrm{OB})$ and the sugarcane bagasse (SB) were collected in the city of Francisco Beltrão, Paraná, Brazil. Initially, both materials were washed with distilled water, dried in a laboratory oven at $70{ }^{\circ} \mathrm{C}$ for $48 \mathrm{~h}$, ground in an industrial blender and sieved for obtaining particles with grain size between 32 and 42 mesh.

Some of the biosorbents were chemically treated with sulfuric acid $\left(\mathrm{H}_{2} \mathrm{SO}_{4}\right)$ at a concentration of 0.5 $\mathrm{mol} / \mathrm{L}$ (Nunes, 2012) to increase the adsorption capacity of the biosorbents by modifying their surfaces. The orange and sugarcane bagasses that received chemical treatment were abbreviated as OBT and SBT, respectively.
In $1000 \mathrm{~mL}$ of a solution containing $0.5 \mathrm{~mol} / \mathrm{L}$ sulfuric acid, $25 \mathrm{~g}$ of biosorbent was added (Nunes 2012). The mixture was shaken at $200 \mathrm{rpm}$ for $3 \mathrm{~h}$ at room temperature, and then the product was filtered, washed with distilled water until having a $\mathrm{pH}$ close to 7 , and dried in an oven at $60^{\circ} \mathrm{C}$ until obtaining a constant weight.

\section{Characterization of the biosorbents}

The morphology of the surface of the biosorbents OB, OBT, SB and SBT was obtained through the analysis of scanning electron microscopy (SEM) (model Tescan VEGA3).

The textural feature of the isotherms was determined by the adsorption and desorption isotherms of nitrogen using the NOVA 2000e-Surface Area \& Pore Size Analyzer instrument, whereas the specific surface area, the pore volume and the mean pore diameter of the materials were determined by BET technique (Brunauer, Emmett and Teller), and the mesoporous distribution was determined by the BJH method.

\section{Experimental design and statistical analysis of the experiment}

A factorial design $2^{3}$ was adopted for the initial phase of the experimental procedures and used for guiding the performance of the tests, which aimed to assess the dye removal by combining three predefined factors (solution $\mathrm{pH}$, chemical treatment and type of biosorbent) and their respective levels (for $\mathrm{pH}$, levels 2 and 5; for chemical treatment, with sulfuric acid and without sulfuric acid; for biosorbent, bagasses from sugar and orange), according to the experimental matrix (Table 1).

The synthetic sewage was produced from the dissolution of the dye Neolan Black WA in distilled water at a concentration $1000 \mathrm{mg} / \mathrm{L}$. The experiments were performed according to the factorial design. For this purpose, in four Erlenmeyer flasks of $250 \mathrm{~mL}, 1.5 \mathrm{~g}$ of the $\mathrm{OB}$ was added in $50 \mathrm{~mL}$ of dye solution at a concentration of $200 \mathrm{mg} / \mathrm{L}$; the $\mathrm{pH}$ of the solutions of two Erlenmeyer flasks was 2 and the $\mathrm{pH}$ of the solutions of two other Erlenmeyer flasks was 5. The same aforementioned procedures were repeated for the other biosorbents (OBT, SB and SBT).

The samples were shaken for 24 hours, then the material was filtered and, finally, the dye concentration of the solution was measured using UV-VIS spectrophotometer (Thermo Scientific, Helios Zeta).

\section{ANALYSIS OF VARIANCE}

For examining whether statistical differences between the effects of the factorial design exist, analysis of variance (ANOVA) was performed. The distribution used for the critical value was F- Fisher 
Table 1. Matrix of the factorial design $2^{3}$ for analysis of dye removal

\begin{tabular}{|c|c|c|c|c|}
\hline \multicolumn{2}{|l|}{ Variables } & Level 1 & \multicolumn{2}{|l|}{ Level 2} \\
\hline \multicolumn{2}{|l|}{$\mathrm{pH}$} & 2 & \multicolumn{2}{|l|}{5} \\
\hline \multicolumn{2}{|c|}{$\mathrm{H}_{2} \mathrm{SO}_{4}(\mathrm{~mol} / \mathrm{L})$} & With & \multicolumn{2}{|l|}{ Without } \\
\hline \multirow{2}{*}{\multicolumn{2}{|c|}{ biosorbent }} & SB & \multicolumn{2}{|l|}{ OB } \\
\hline & & Variables & & \\
\hline Experiment & Replicate & $\mathrm{pH}$ & $\mathrm{H}_{2} \mathrm{SO}_{4}$ & Biosorbent \\
\hline 1 & 1 & 2 & Without & SB \\
\hline 2 & 1 & 5 & Without & SB \\
\hline 3 & 1 & 2 & With & SB \\
\hline 4 & 1 & 5 & With & SB \\
\hline 5 & 2 & 2 & Without & SB \\
\hline 6 & 2 & 5 & Without & SB \\
\hline 7 & 2 & 2 & With & $\mathrm{SB}$ \\
\hline 8 & 2 & 5 & With & SB \\
\hline 9 & 1 & 2 & Without & OB \\
\hline 10 & 1 & 5 & Without & OB \\
\hline 11 & 1 & 2 & With & OB \\
\hline 12 & 1 & 5 & With & OB \\
\hline 13 & 2 & 2 & Without & OB \\
\hline 14 & 2 & 5 & Without & OB \\
\hline 15 & 2 & 2 & With & $\mathrm{OB}$ \\
\hline 16 & 2 & 5 & With & OB \\
\hline
\end{tabular}

(once the effects are fixed) and the significance level $(\alpha)$ considered was $5 \%$. When the calculated $\mathrm{F}$ is greater than the critical $\mathrm{F}$, the null hypothesis $\mathrm{H} 0$ must be rejected and the alternative hypothesis accepted. A problem with three factors has seven hypotheses, which must be tested as follows (Cna 2018):

$\mathrm{H}_{0}: \alpha_{1}=\alpha_{2}=\ldots=\alpha_{\mathrm{a}}=0$

$\mathrm{H}_{1}: \alpha_{\mathrm{i}} \neq 0$, that is, at least the effect of a main factor level A differs from zero.

$\mathrm{H}_{0}: \beta_{1}=\beta_{2}=\ldots=\beta_{\mathrm{b}}=0$

$\mathrm{H}_{1}: \beta_{\mathrm{j}} \neq 0$, that is, at least the effect of a main factor level $\mathrm{B}$ differs from zero.

$\mathrm{H}_{0}: \mathrm{Y}_{11}=\mathrm{\gamma}_{12}=\ldots=\mathrm{\gamma}_{\mathrm{ab}}=0$

$\mathrm{H}_{1}: \gamma_{\mathrm{k}} \neq 0$, that is, at least the effect of a main factor level $\mathrm{C}$ differs from zero.

$\mathrm{H}_{0}: \alpha \beta_{11}=\alpha \beta_{12}=\ldots=\alpha \beta_{\mathrm{ab}}=0$

$\mathrm{H}_{1}: \alpha \beta_{\mathrm{ij}} \neq 0$, that is, at least the effect of a pair of levels

$i, j$ of the interaction of the factors $A$ and $B$, respectively, differs from zero.

$\mathrm{H}_{0}: \alpha \gamma_{11}=\alpha \gamma_{12}=\ldots=\alpha \gamma_{\text {ac }}=0$

$\mathrm{H}_{1}: \alpha \gamma_{\mathrm{ik}} \neq 0$, that is, at least the effect of a pair of levels

$\mathrm{i}, \mathrm{k}$ of the interaction of the factors $\mathrm{A}$ and $\mathrm{C}$, respectively, differs from zero.

$\mathrm{H}_{0}: \beta \mathrm{Y}_{11}=\beta \mathrm{Y}_{12}=\ldots=\beta \mathrm{Y}_{\mathrm{bc}}=0$

$\mathrm{H}_{1}: \beta \gamma_{\mathrm{ik}} \neq 0$, that is, at least the effect of a pair of levels

$\mathrm{j}, \mathrm{k}$ of the interaction of the factors $\mathrm{B}$ and $\mathrm{C}$, respectively, differs from zero.

$\mathrm{H}_{0}: \alpha \beta \mathrm{Y}_{111}=\alpha \beta \mathrm{Y}_{112}=\ldots=\alpha \beta \mathrm{Y}_{\mathrm{abc}}=0$
$\mathrm{H}_{1}: \alpha \beta \gamma_{\mathrm{ijk}} \neq 0$, that is, at least the effect of a trio of levels $\mathrm{i}, \mathrm{j}, \mathrm{k}$ of the interaction of the factors $\mathrm{A}, \mathrm{B}$ and $\mathrm{C}$, respectively, differs from zero.

In which:

(a) $\alpha_{i}=$ effect of the i level of the factor $A$;

(b) $\beta_{\mathrm{j}}=$ effect of the $\mathrm{j}$ level of the factor $\mathrm{B}$;

(c) $\gamma_{k}=$ effect of the $k$ level of the factor C;

(d) $(\alpha \beta)_{\mathrm{ij}}=$ effect of the interaction of the factors $\mathrm{A}$ and $\mathrm{B}$;

(e) $(\alpha \gamma)_{i k}=$ effect of the interaction of the factors A and $\mathrm{C}$;

(f) $(\beta \gamma)_{j k}=$ effect of the interaction of the factors B and $\mathrm{C}$

(g) $(\alpha \beta \gamma)_{\mathrm{ijk}}=$ effect of the interaction of the three factors $\mathrm{A}, \mathrm{B}$ and $\mathrm{C}$;

Another way to study the rejection or accept rate of $\mathrm{H}_{0}$ is by using the p-value, which can be generated by the Software Statistica 13.2. According to Montgomery (2016), the p-value corresponds to the lowest significance level that leads to rejection of the null hypothesis $\mathrm{H}_{0}$ for the data reported. When the $\mathrm{p}$ value is lower than the significance level chosen, the null hypothesis $\mathrm{H}_{0}$ is rejected (Cardoza Galdámez 2002).

ANOVA can be presented in tables or boxes; therefore, Table 2 shows a representation of ANOVA for a factorial design with three factors, each factor with two levels.

The main effects and can be calculated based on the number of levels of the factor A (a), in the number of levels of the factor B (b), the number of levels of the factor $\mathrm{C}$ (c) and in the number of experiments (n) according to the presented with the equations Eq. (1), (2) and Eq. (3), respectively (Montgomery 2016). Main effect of the factor $A\left(E_{1}\right), \mathbf{E q . ~ 1 : ~}$

$$
E_{1}=\frac{1}{4 n}[a+a b+a c+a b c-(-1)-b-c-b c]
$$

In which: $\mathrm{a}=$ number of levels in the factor $\mathrm{A}, \mathrm{b}=$ number of levels in the factor $\mathrm{B}, \mathrm{c}=$ number of levels in the factor $\mathrm{C}, \mathrm{n}=$ number of experiments performed (replicates).

Main effect of the factor A $\left(E_{2}\right)$, Eq. 2:

$$
E_{2}=\frac{1}{4 n}[b+a b+b c+a b c-(-1)-a-b-a c]
$$

Main effect of the factor $A\left(E_{3}\right), \mathbf{E q} \cdot \mathbf{3}$ :

$$
E_{3}=\frac{1}{4 n}[c+a c+b c+a b c-(-1)-a-b-a b]
$$

Second-order interaction effect between the factor $\mathrm{A}$ and the factor B $\left(\mathrm{E}_{12}\right)$, Eq. 4 :

$$
E_{12}=\frac{1}{4 n}[a b c-b c+a b-b-a c+c-a+(1)]
$$

Second-order interaction effect between the factor and the factor $\mathrm{C}\left(\mathrm{E}_{13}\right), \mathbf{E q .} \mathbf{5}$ : 
Table 2. Analysis of variance (ANOVA) for a factorial design $2^{3}$.

\begin{tabular}{|c|c|c|c|c|}
\hline Variation source (SV) & $\begin{array}{l}\text { Degrees of freedom } \\
\text { (DF) }\end{array}$ & $\begin{array}{l}\text { Sum of square } \\
\text { (SS) }\end{array}$ & $\begin{array}{l}\text { Medium Squares } \\
\text { (MS) }\end{array}$ & F calculated \\
\hline \multicolumn{5}{|l|}{ Main Effects } \\
\hline Factor A (E1) & 1 & SSE1 & MA E1 = SS E1/1 & MA E1/ MsE \\
\hline Factor B (E2) & 1 & SSE2 & MS E2 = SS E2 /1 & MS E2 / MsE \\
\hline Factor C (E3) & 1 & SSE3 & MS E3 = SS E3 /1 & MS E3 / MsE \\
\hline \multicolumn{5}{|l|}{ Two-factor interaction } \\
\hline Factor A * Factor B (E12) & 1 & SSE12 & MS E12 = SS E12 /1 & MS E12 / MsE \\
\hline Factor A * Factor C (E13) & 1 & SSE13 & MS E13 = SS E13 /1 & MS E13 / MsE \\
\hline Factor B * Factor C (E23) & 1 & SSE23 & MS E23 = SS E23 /1 & MS E23 / MsE \\
\hline \multicolumn{5}{|l|}{ Three-factor interaction } \\
\hline Factor A * Factor B *Factor C (E123) & 1 & SSE123 & MS E123 = SS E123 /1 & MS E123/ MsE \\
\hline Error & $23(n-1)$ & SSE & MsE & \\
\hline Total & n23-1 & SST & & \\
\hline
\end{tabular}

$$
E_{13}=\frac{1}{4 n}[a b c-b c+a c-c-a b+b-a+(1)]
$$

Second-order interaction effect between the factor B and the factor $\mathrm{C}\left(\mathrm{E}_{23}\right)$, Eq. 6:

$$
E_{23}=\frac{1}{4 n}[a b c-a c+b c-c-a b-b+a+(1)]
$$

Third-order interaction effect between the Factor A, the factor $B$ and the $C$ Factor $\left(E_{123}\right)$, Eq. 7:

$$
E_{123}=\frac{1}{4 n}[a b c-b c-a c+c-a b+b+a-(1)]
$$

The sum of the squares (SS) for each of the effects is calculated as shown in Eq. (8), being (k) the number of treatments (Montgomery 2016).

$$
S S_{E 12, \ldots, K}=\frac{\left(E_{12, \ldots, K}\right)^{2}}{n 2^{K}}
$$

The total sum of squares and the sum of the squared errors shown in Table 2 can be calculated according to Eq. (9) and Eq. (10), respectively (Hines et al. 2006).

$$
\begin{aligned}
& \mathrm{SST}=\sum_{i=1}^{a} \sum_{j=1}^{b} \sum_{k=1}^{c} \sum_{l=1}^{n} y_{i j k l}{ }^{2}-\frac{y \ldots{ }^{2}}{a b c n} \\
& \mathrm{SS}_{\mathrm{T}}=\mathrm{SS}_{\mathrm{E} 1}+\mathrm{SS}_{\mathrm{E} 2}+\mathrm{SS}_{\mathrm{E} 3}+\mathrm{SS}_{\mathrm{E} 12}+\mathrm{SS}_{\mathrm{E} 13}+ \\
& \mathrm{SS}_{\mathrm{E} 123}+\mathrm{SS}_{\mathrm{E}}
\end{aligned}
$$

According to Devore et al. (2018) the model for the three-factor experiment $\mathrm{r}$ is given by Eq. (11).

$$
\begin{aligned}
& y_{i j k l}=\mu+\alpha_{i}+\beta_{j}+\gamma_{k}+(\alpha \beta)_{i j}+(\alpha \gamma)_{i k}+(\beta \gamma)_{j k} \\
& +(\alpha \beta \gamma)_{i j k}+(\epsilon)_{i j k l}
\end{aligned}
$$

In which: $\mu=$ the global average, and $\epsilon_{\mathrm{ijk}}=$ random error of each observation.
The application of ANOVA requires some assumptions, in which errors are considered random, from a normal distribution, independent, with mean zero and constant variance $\sigma 2$ (CaladoandMontgomery 2003). The normality of the errors can be verified using a normal probability plot of residuals, and the closer to the continuous line the points obtained in the experiments are, the greater the normality assumption of the residuals (CaladoandMontgomery 2003).

For the homogeneity of variance test (constant $\sigma 2)$, the Barlett's test was used. The independence between the observations was ensured during the experiments. When ANOVA indicates significant statistical difference between the group(s), the complementary tests, which are called multiple comparison tests of means and seek to identify which are the groups that differ, are used. One of the most used tests is Tukey's HSD (Tukey's honest significant difference) (Montgomery 2016).

\section{RESULTS AND DISCUSSIONS}

\section{Scanning electron microscopy (SEM)}

SEM analysis allow informing and determining some characteristics of solid materials, such as their composition, texture and topography. The micrograph of the biosorbent SB can be seen in Fig. 1, in which it was captured at 104 times magnification.

The analysis of the image shows SB is composed of two structures regarded as the main structures; the fiber and the marrow, which are identified in Fig. 1a. Figure 1b. shows the micrograph of SBT, captured at 100 times magnification. The marrows were damaged by the acid action, and, consequently, their number was reduced. On the fibers, parallel stripes were partially degraded, becoming more exposed. This may occur because the fibers are composed primarily of cellulose, hemicellulose and lignin and the chemical treatment 
with sulfuric acid removes their hemicellulose, causing structural changes in lignin and thus increasing the BET surface area and the pore size (Schimmel et al. 2010, Rangabhashiyam et al. 2013).

Figure 2a shows the micrograph of $\mathrm{OB}$, captured at 1000 times magnification. Analyzing the image, OB had corrugations in its cell walls, with uneven surface and large intercellular spaces, similar to the features found by Fernandez et al. (2014). Figure 2b shows the micrograph of OBT, captured at 1000 times magnification, in which the acid action promoted a change in the structure of the orange particles, becoming them flatter and smoother. Therefore, the result from SEM demonstrates that $\mathrm{OB}$ has a better morphology for adsorption, once the contact area before the chemical treatment was greater due to the corrugations of the material.

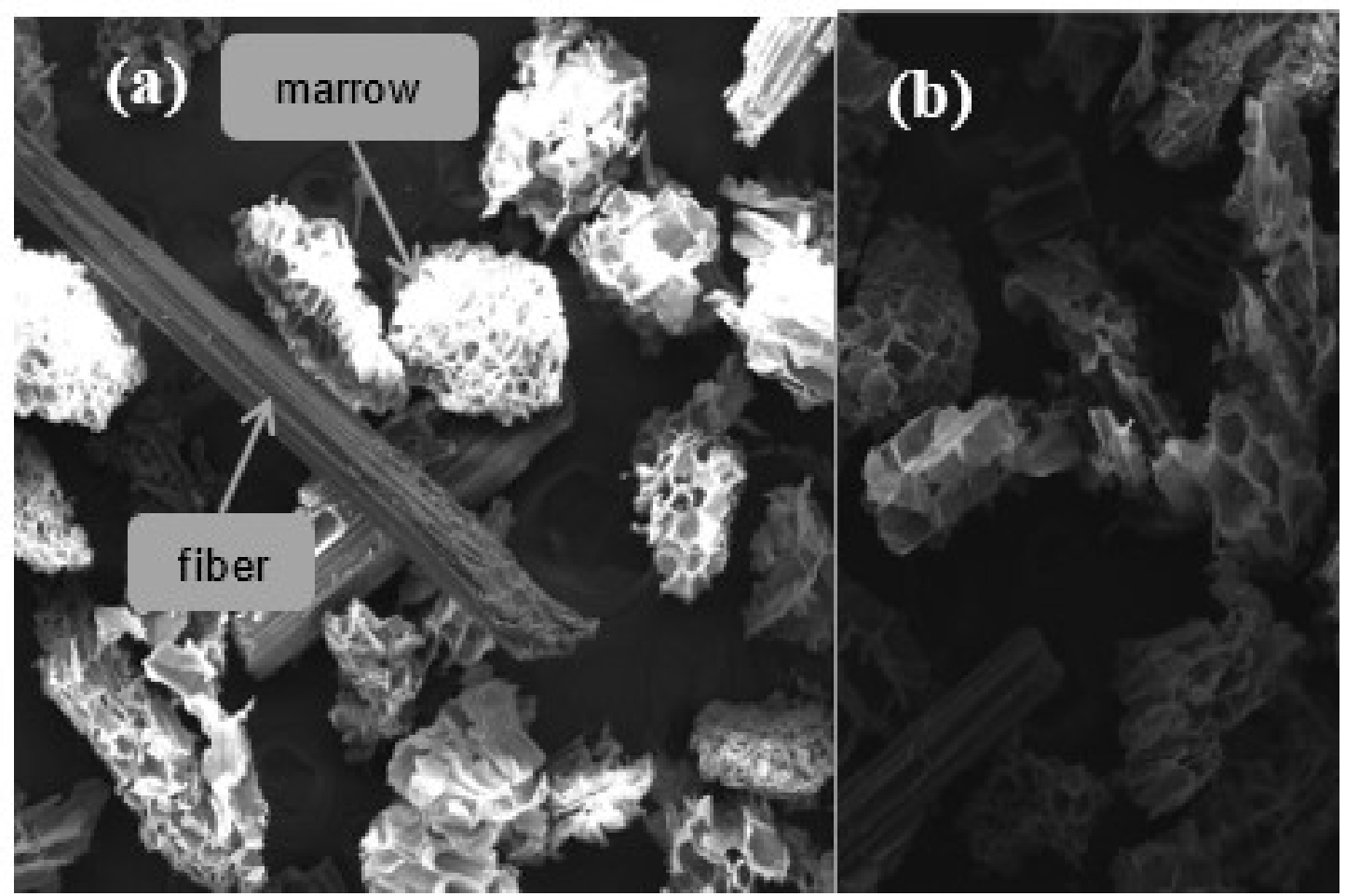

Fig. 1 Analysis of the micrograph of sugarcane using SEM (a) SB 104 times magnification; (b) SBT 100 times magnification.

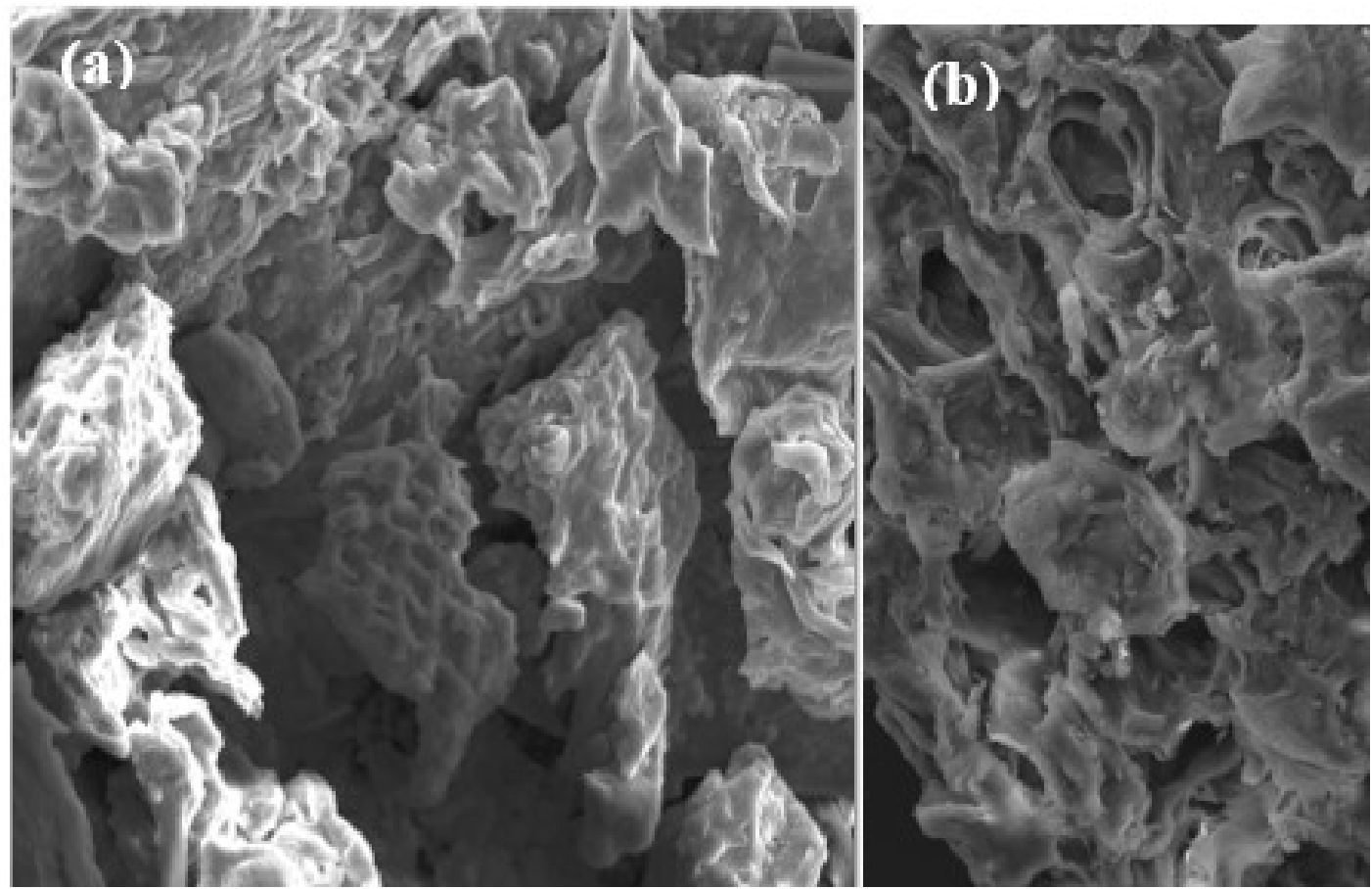

Fig. 2 Analysis of the micrograph of orange using SEM (a) OB 1000 times magnification; (b) OBT 1000 times magnification 
Adsorption and desorption isotherms of $\mathrm{N}_{2}$ (BET/BJH)

The values of surface area, pore diameter and total volume, obtained through adsorption and desorption isotherms of nitrogen (BET/BJH) of the biosorbents SB and OB, are expressed in Table 3. In Table 3, the BET surface area of $\mathrm{OB}$ is greater than that of SB (1.813 $\mathrm{m}^{2} \cdot \mathrm{g}^{-1}$ and $0.684 \mathrm{~m}^{2} \cdot \mathrm{g}^{-1}$, respectively). The larger the surface area BET more polluting solid surface can remove, however, the potential of removing the adsorbate dependent on the surface area of the solid, but also its pore volume, so that the dye requires superior porosities due to its extensive structure.

\section{Analysis of adsorption}

By using the factorial design, the influence of the chemical treatment of the biosorbent, of the solution $\mathrm{pH}$ and of the type of biosorbent on adsorption processes of the dye Neolan Black WA at $200 \mathrm{mg}$. $\mathrm{L}^{-1}$ was verified.

Table 4 shows the results obtained for dye removal, in which the best conditions for dye removal using the sugarcane bagasse were found in the experiment 3 and its replicate and in the experiment 7, in which the solution $\mathrm{pH}$ was 2 , and $\mathrm{SB}$ had received chemical treatment. In both cases, the dye removal was greater than $99 \%$. Table 4 shows the best conditions for the removal of the dye Neolan Black WA using orange bagasse were found in the experiments 9 and 13, in which the solution $\mathrm{pH}$ was 2 and the $\mathrm{OB}$ had not received chemical treatment. In both cases, the dye removal was greater than $64 \%$.

\section{Statistical analysis of the experiment}

The analysis of variance (ANOVA) was performed to check whether there were statistical differences between the effects of the factorial design at a significance level $(\alpha)$ of $5 \%$. As already mentioned, ANOVA requires some assumptions. For this purpose, the normality, homogeneity and independence of the errors were analyzed; normality was checked using a normal probability plot of residuals, shown in Fig. 3, in which the values are close to the normal straight line. Thus, the normality assumption of the data is met.

For the homogeneity of variance (constant $\sigma^{2}$ ) test, the Cochran C, Hartley and Bartlett tests were used, in which the data were considered homogeneous, because the null hypothesis $\mathrm{H}_{0}$ for the variance equality between the means was accepted $\left(\mathrm{H}_{0}: \sigma_{1}^{2}=\sigma_{2}^{2}=\ldots=\sigma_{n}^{2}\right)$ at a significance level of 0.101 . The independence between the observations was ensured during the experiments. Thus, the analysis of variance presented is valid and the results obtained for such ANOVA are shown in Table 5.

Table 1. Results obtained through adsorption and desorption isotherms of nitrogen (BET/BJH) for the biosorbents $\mathrm{SB}$ and $\mathrm{OB}$

\begin{tabular}{lll}
\hline Adsorbent & SB & OB \\
\hline $\begin{array}{l}\text { Surface area } \\
(\mathrm{BET})\left(\mathrm{m}^{2} \cdot \mathrm{g}^{-1}\right)\end{array}$ & 0.684 & 1.813 \\
$\begin{array}{l}\text { Total pore } \\
\text { volume }\left(\mathrm{cm}^{3} \cdot \mathrm{g}^{-1}\right)\end{array}$ & $1.283 \times 10^{-3}$ & $1.766 \times 10^{-3}$ \\
Pore diameter $(\AA)$ & 37.52 (mesoporous) & 19.48 (micropores) \\
\hline
\end{tabular}

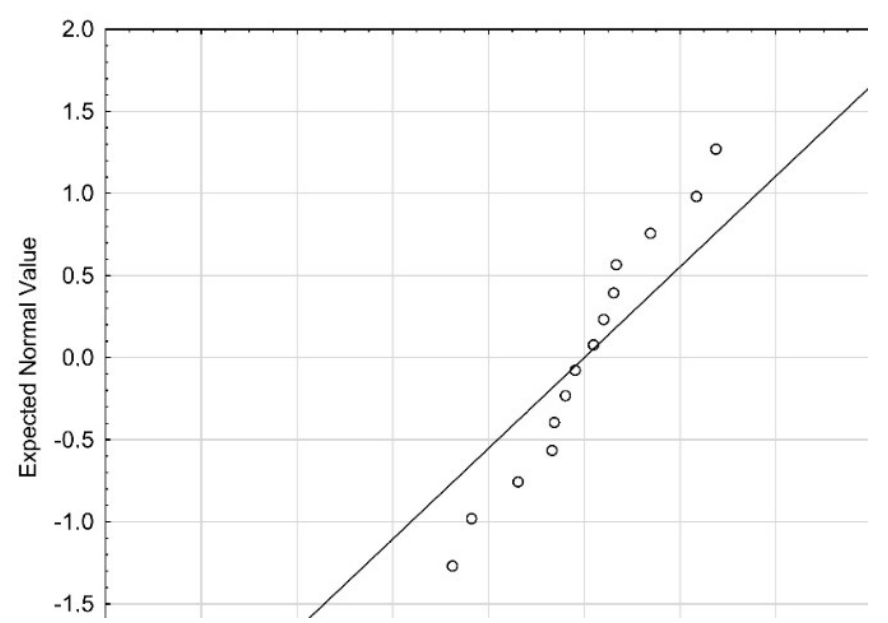

Fig. 2 Normal probability plot of residuals

Table 2. Matrix of the factorial design 23 for analysis of dye removal

\begin{tabular}{|c|c|c|c|c|c|}
\hline \multicolumn{2}{|l|}{ Variables } & \multicolumn{2}{|r|}{ Level 1} & \multicolumn{2}{|r|}{ Level 2} \\
\hline \multicolumn{2}{|l|}{$\mathrm{pH}$} & \multicolumn{2}{|r|}{2} & \multicolumn{2}{|r|}{5} \\
\hline \multicolumn{2}{|c|}{$\mathrm{H}_{2} \mathrm{SO}_{4}(\mathrm{~mol} / \mathrm{L})$} & \multicolumn{2}{|r|}{ With } & \multicolumn{2}{|r|}{ Without } \\
\hline \multicolumn{2}{|l|}{ Biosorbent } & \multicolumn{2}{|r|}{ Sugarcane } & \multicolumn{2}{|r|}{ Orange } \\
\hline \multirow[b]{2}{*}{ Experiment } & \multirow[b]{2}{*}{ Replicate } & \multicolumn{2}{|c|}{ Variables } & \multirow[b]{2}{*}{ Biosorbent } & \\
\hline & & $\mathrm{pH}$ & $\mathrm{H}_{2} \mathrm{SO}_{4}$ & & Response \\
\hline 1 & 1 & 2 & Without & SB & 96.12 \\
\hline 2 & 1 & 5 & Without & SB & 92.33 \\
\hline 3 & 1 & 2 & With & SB & 100.0 \\
\hline 4 & 1 & 5 & With & SB & 89.16 \\
\hline 5 & 2 & 2 & Without & SB & 95.50 \\
\hline 6 & 2 & 5 & Without & SB & 95.08 \\
\hline 7 & 2 & 2 & With & SB & 99.33 \\
\hline 8 & 2 & 5 & With & SB & 87.78 \\
\hline 9 & 1 & 2 & Without & OB & 64.48 \\
\hline 10 & 1 & 5 & Without & OB & 61.59 \\
\hline 11 & 1 & 2 & With & OB & 58.46 \\
\hline 12 & 1 & 5 & With & OB & 57.98 \\
\hline 13 & 2 & 2 & Without & OB & 64.67 \\
\hline 14 & 2 & 5 & Without & OB & 63.94 \\
\hline 15 & 2 & 2 & With & OB & 50.69 \\
\hline 16 & 2 & 5 & With & OB & 58.38 \\
\hline
\end{tabular}


Table 3. Analysis of variance (ANOVA) for the factorial design $2^{3}$

\begin{tabular}{|c|c|c|c|c|c|c|}
\hline Source of variation (SV) & $\begin{array}{c}\text { Degrees of } \\
\text { freedom (DOF) }\end{array}$ & $\begin{array}{l}\text { Sum of squares } \\
\text { (SS) }\end{array}$ & $\begin{array}{c}\text { Mean Squares } \\
\text { (MS) }\end{array}$ & calculated $\mathbf{F}$ & p-value & \\
\hline \multicolumn{7}{|l|}{ Main Effects } \\
\hline $\mathrm{pH}$ & 1 & 33.09 & 33.09 & 6.93 & 0.030 & $* *$ \\
\hline $\mathrm{H}_{2} \mathrm{SO}_{4}$ & 1 & 63.72 & 63.72 & 13.35 & 0.006 & $* *$ \\
\hline Biosorbent & 1 & 4730.34 & 4730.34 & 990.76 & 0.000 & $* *$ \\
\hline \multicolumn{7}{|l|}{ Two-factor interaction } \\
\hline $\mathrm{pH}^{*} \mathrm{H}_{2} \mathrm{SO}_{4}$ & 1 & 3.38 & 3.38 & 0.71 & 0.425 & \\
\hline $\mathrm{pH}^{*}$ Biosorbent & 1 & 56.96 & 56.96 & 11.93 & 0.009 & $* *$ \\
\hline $\mathrm{H}_{2} \mathrm{SO}_{4} *$ Biosorbent & 1 & 43.59 & 43.59 & 9.13 & 0.017 & $* *$ \\
\hline \multicolumn{7}{|l|}{ Three-factor interaction } \\
\hline $\mathrm{pH}^{*} \mathrm{H}_{2} \mathrm{SO}_{4} *$ Biosorbent & 1 & 52.60 & 52.60 & 11.02 & 0.011 & $* *$ \\
\hline Error & 8 & 38.20 & 4.77 & & & \\
\hline
\end{tabular}

The effect of the interaction between the three factors was significant, thus, the main effects and those from the interactions of only two factors that were also significant do not need to be interpreted alone. Fig. 4 shows the Pareto chart of standardized effects, which classifies the effects as significant or not, for a $\alpha=0.05$, so that the horizontal bars that cross the vertical red line are considered significant. The Pareto chart complements visually the data shown in Table 5, thus, only the interaction between $\mathrm{pH}$ and sulfuric acid was not considered significant. The Tukey's HSD test was used for identification of the effects that differ in the interaction between $\mathrm{pH}$, chemical treatment and biosorbent. The test result is shown in Table 6.

At first, Table 6 shows that the dye removal means in all experiments for which SB was used were higher, even in the experiment with $\mathrm{OB}$ that had the same conditions regarding the levels of chemical treatment and the solution $\mathrm{pH}$. Therefore, the type of biosorbent used was one of the most influential factors in the difference between the effects, noting that no effect of treatment with SB received the same letter that the effects of treatment with $\mathrm{OB}$ received; hence, the effects for these factors were statistically different at a significance level of $5 \%$.

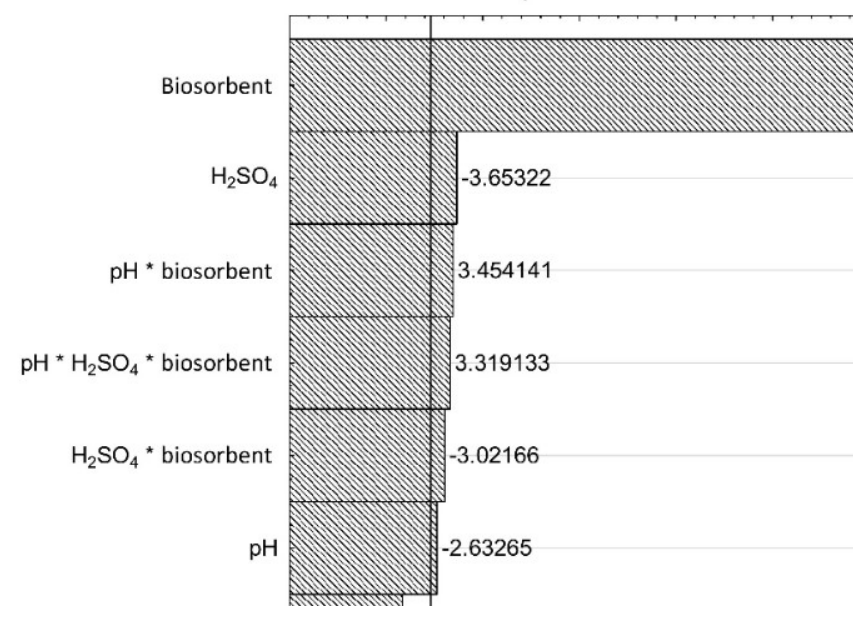

Fig. 3 Pareto chart of standardized effects for an $\alpha$ of $5 \%$
Table 4. Homogeneous groups of Tukey's test

\begin{tabular}{llllll}
\hline Experiments & $\mathrm{pH}$ & $\mathrm{H}_{2} \mathrm{SO}_{4}$ & Biosorbent & Means & $\begin{array}{l}\text { Tukey } \\
\text { group }\end{array}$ \\
\hline 1 e 5 & 2 & Without & $\mathrm{SB}$ & 95.81 & $\mathrm{ab}$ \\
2 e 6 & 5 & Without & $\mathrm{SB}$ & 93.71 & $\mathrm{ab}$ \\
3 e 7 & 2 & With & $\mathrm{SB}$ & 99.67 & $\mathrm{a}$ \\
4 e 8 & 5 & With & $\mathrm{SB}$ & 88.47 & $\mathrm{~b}$ \\
9 e 13 & 2 & Without & OB & 64.575 & $\mathrm{c}$ \\
10 e 14 & 5 & Without & OB & 62.765 & cd \\
11 e 15 & 2 & With & OB & 54.575 & $\mathrm{~d}$ \\
12 e 16 & 5 & With & OB & 58.180 & cd \\
\hline
\end{tabular}

Equal letters do not statistically differ among themselves at $\alpha$ of $5 \%$.

The unfolding of the treatments was performed and, to this end, the first level of the biosorbent was set, as the biosorbent factor showed a greater influence on the dye removal. Then, the first level of the $\mathrm{pH}$ factor was set and, finally, all the levels of chemical treatment were combined. Thereafter, the biosorbent was the same, but the second $\mathrm{pH}$ level was set and, again, all the levels of chemical treatment were combined.

All these aforementioned steps were repeated for the second level of biosorbent, constantly observing the statistically different means. The results from the unfolding with the level of biosorbent set for sugarcane is shown in Table 7, whereas for orange are presented in Table 8.

Table 7 shows when the biosorbent factor is fixed for the level sugar cane and the $\mathrm{pH}$ level set is 2, that is, varying only the chemical treatment levels (results expressed in first line of means), a statistical difference between the effects is not obtained, because the means of the treatments were statistically similar at a significance level of $5 \%$. The same situation occurred when the $\mathrm{pH}$ set was 5 , and only the levels of the chemical treatment varied.

When the biosorbent factor remained the same for the level sugarcane and the chemical treatment was in the level "with", that is, varying only the solution $\mathrm{pH}$ (the second column of the chemical treatment), a 
significant statistical difference between the effects of treatment was observed, and the mean for the color removal was higher when the material had received chemical treatment and was in a solution of $\mathrm{pH} 2$.

Table 8 shows when fixing the biosorbent factor in the level orange, the $\mathrm{pH}$ in 2 and only varying chemical treatment levels, a statistical difference between the effects (difference of lowercase letters for the first line) was obtained, because the means of the treatments differed statistically at a significance level of $5 \%$, and the higher means of dye removal at $\mathrm{pH} 2$ occurred when the orange had not received chemical treatment; therefore, the chemical treatment for this $\mathrm{pH}$ and the type of biosorbent influenced negatively on the dye removal for $\alpha=5 \%$.

When fixing the biosorbent factor for the level orange without chemical treatment, that is, varying only the solution $\mathrm{pH}$, significant statistical difference between the effects of the treatment were not observed, the same situation occurred when fixing the biosorbent factor in the level orange with chemical treatment, varying only the solution $\mathrm{pH}$.

\section{CONCLUSION}

By characterizing the biosorbents, the chemical treatment with $0.5 \mathrm{~mol} / \mathrm{L}$ sulfuric acid modified the surface structures of the biosorbents. Based on the experiments performed according to the factorial design $2^{3}$, a statistical significant difference for dye removal was observed when comparing the sugarcane biosorbent with the orange biosorbent; sugarcane removed more dye, reaching more than $99 \%$ when combined with the

Table 5. Unfolding with fixed biosorbent factor for the level sugarcane

\begin{tabular}{l|lc}
\hline \multicolumn{3}{c}{ Biosorbent: SB } \\
\hline \multirow{3}{*}{$\mathrm{pH}$ levels } & \multicolumn{3}{|c}{ Chemical treatment } \\
\cline { 2 - 3 } 2 & Without & With \\
5 & $95.810 \mathrm{aA}$ & $99.665 \mathrm{aA}$ \\
\hline Mean values in the same column, followed by identical \\
uppercase letters, or in a same line, followed by identical \\
lowercase letters, do not differ at the significance level of 5\% by \\
Tukey test.
\end{tabular}

Table 6 Unfolding with fixed biosorbent factor for the level orange

\begin{tabular}{l|ll}
\hline \multicolumn{3}{c}{ Biosorbent: OB } \\
\hline \multirow{3}{*}{$\mathrm{pH}$ levels } & Chemical treatment \\
\cline { 2 - 3 } 2 & Without & With \\
5 & $64.575 \mathrm{aA}$ & $54.575 \mathrm{bA}$ \\
\hline
\end{tabular}

Mean values expressed in the same column, followed by identical uppercase letters, or in a same line, followed by identical lowercase letters, do not differ at the significance level of $5 \%$ by Tukey test. solution $\mathrm{pH} 2$ and with the chemical treatment. Although orange has not been shown to be as effective as sugarcane, it presented a satisfactory dye adsorption, greater than $50 \%$. The unfolding of the Tukey test demonstrated that the solution $\mathrm{pH} 2$ significantly and positively influenced the dye removal when the cane had received chemical treatment, this being the best experimental condition. The unfolding of the Tukey test for orange showed that the chemical treatment significantly and negatively influenced the dye removal when the solution $\mathrm{pH}$ was 2 . Thus, this experimental condition should be avoided. SEM and BET showed that the chemical treatment changed the chemical structure of the materials, and for the biosorbent made from sugarcane bagasse this acid alteration was positive, increasing the surface contact area between the adsorbent and the adsorbate, which cannot be reported for the adsorbent made from orange bagasse, considering that the acid chemical treatment promoted a reduction in the contact area between the pollutant and the adsorbent.

Acknowledgment We gratefully acknowledge the Research Support Program of the Federal Technological University of Paraná (UTFPR) - Campus Francisco Beltrão.

\section{REFERENCES}

Agarwal, S., S. Vilvanathan and S. Shanthakumar (2019). Adsorption Kinetics, Isotherms, Thermodunamics Studies on the Removal of Congo Red Dye Using Annona Squamosa (Custard Apple) Peel. Journal of Urban and Environmental Engineering 13(2): 228-234.

Brasil, M. D. M. a.-. (2005). Conama - Conselho Nacional Do Meio Ambiente. Resolução № 357 De 17 De Março De 2005.

Brasil, M. D. M. A. (2011). Conama - Conselho Nacional Do Meio Ambiente. Resolução No 430 De 13 De Maio De 2011.

Brasil, P. N. D. M. a.-. (1981). Lei No 6938, De 31 De Agosto De 1981 - Politica Nacional Do Meio Ambiente.

Calado, V. and D. C. Montgomery (2003). Planejamento De Experimentos Usando O Statistica, E-papers.

Cardoza Galdámez, E. V. (2002). Aplicação Das Técnicas De Planejamento E Análise De Experimentos $\mathrm{Na}$ Melhoria $\mathrm{Da}$ Qualidade De Um Processo De Fabricação De Produtos Plásticos. Application design of experiments in the injection molding process.

Cna, C. D. a. E. P. D. B.-. (2018). "Bovinocultura De Corte Balanço 2018." Retrieved 20 de janeiro de 2019, 2019, from https://www.cnabrasil.org.br/assets/images/31BOVINOCULTURA-DE-CORTE_vf.pdf.

Devore, J. L. (2018). Probabilidade E Estatística Para Engenharia E Ciências. São Paulo, Cengage Learning.

Fernandez, M. E., G. V. Nunell, P. R. Bonelli and A. L. Cukierman (2014). Activated Carbon Developed from Orange Peels: Batch and Dynamic Competitive Adsorption of Basic Dyes. Industrial Crops and Products 62: 437-445.

Hines, W. W., D. C. Montgomery, D. Goldsman and C. M. Borror (2006). Probabilidade E Estatística Na Engenharia. Rio de Janeiro, LTC. 
Iap, I. a. D. P. (2009). Resolução Cema 70/2009 - Condições E Padrões De Lançamento De Efluentes Líquidos Industriais.

Leme, E. J. D. A. (2014). Manual Prático De Tratamento De Águas Residuárias, EdUFSCar.

Montgomery, D. C. (2016). Estatística Aplicada E Probabilidade Para Engenheiros. Rio de Janeiro, LTC.

Nunes, J. A. (2012). Tratamento Físico-Químico De Águas Residuárias Industriais. ARACAJU.

Palma, J. S. L. D. (2016). Efluentes Industriais Da Schmidt Light Metal, Fundição Injetada, Lda, Universidade de Aveiro.

Rangabhashiyam, S., N. Anu and N. Selvaraju (2013). Sequestration of Dye from Textile Industry Wastewater Using Agricultural
Waste Products as Adsorbents. Journal of Environmental Chemical Engineering 1(4): 629-641.

Schimmel, D., K. C. Fagnani, J. B. O. D. Santos, M. a. S. D. Barros and E. a. D. Silva (2010). Adsorption of Turquoise Blue Qg Reactive Bye Commercial Activated Carbon in Batch Reactor: Kinetic and Equilibrium Studies. Brazilian Journal of Chemical Engineering 27: 289-298.

Vijayaraghavan, J., S. J. S. Basha and J. Jegan (2013). A Review on Efficacious Methods to Decolorize Reactive Azo Dye. Journal of Urban and Environmental Engineering 7(1): 30-47. 